\title{
A política pública de educação e o enfrentamento à violência sexual contra crianças e adolescentes em Manaus/AM: desafios diante das legislações ${ }^{1}$
}

\author{
Claudiney Lofiego Cacau² \\ Márcio de Oliveira ${ }^{3}$ \\ Iolete Ribeiro da Silva ${ }^{4}$
}

\section{Resumo}

A violência sexual é uma violação de Direitos Humanos de crianças e adolescentes muito frequente no Brasil e tem ocupado significativo espaço na grande mídia e debates acadêmicos. Esta pesquisa buscou compreender quais são as responsabilidades da política pública de educação no enfrentamento da violência sexual contra crianças e adolescentes com base na Lei no 13.431/2017 e Decreto no 9.603/2018. Também buscou-se identificar se estas legislações dialogam com as metas e estratégias do Plano Municipal de Educação do município de Manaus/AM. Após a análise do PME do município de Manaus/AM, verificou-se que apenas uma única estratégia de ensino estratégia 7.25 - menciona a questão da violência sexual, configurando um contexto de diálogo e debate de pouca visibilidade no âmbito escolar.

Palavras-chave: Violência Sexual; Plano Municipal de Educação; Amazônia.

Public policy on education and addressing sexual violence against children and adolescents: challenges before legislation

\section{Abstract}

Sexual violence is a violation of human rights of children and adolescents very frequent in Brazil and has occupied significant space in the mainstream media and academic debates. This research sought to understand what are the responsibilities of public education policy in coping with sexual violence against children and adolescents based on Law no. 13.431/2017 and Decree no. 9.603/2018. We also sought to identify whether these laws dialogue with the goals and strategies of the Municipal Education Plan of the municipality of Manaus/AM. After the analysis of the SME of the municipality of Manaus / AM, it was found that only a single teaching strategy - strategy 7.25 - mentions the issue of sexual violence, configuring a context of dialogue and debate of little visibility in the school environment. Keywords: Sexual Violence; Municipal Education Plan; Amazon.

\section{Introdução}

A violência sexual é uma violação de direitos humanos de crianças e adolescentes muito frequente no Brasil e tem ocupado significativo espaço nas grandes mídias - televisão, rádio -e

\footnotetext{
${ }^{1}$ Texto produzido a partir de financiamento do órgão de fomento FAPEAM, Conselho Nacional de Desenvolvimento Científico e Tecnológico - CNPq (Bolsa Produtividade) e apoio da CAPES.

${ }^{2}$ Universidade Federal do Amazonas, Manaus/AM, claudineylofiego36@gmail.com.

${ }^{3}$ Universidade Federal do Amazonas, Manaus/AM, marcio.1808@hotmail.com

${ }^{4}$ Universidade Federal do Amazonas, Manaus/AM, ioleteribeiro@ufam.edu.br.
} 
debates acadêmicos qual sejam, Minayo (2006), Oliveira (2017), Silva e Oliveira (2020), entre outros/as. Apesar de atingir todas as regiões do país e classes sociais algumas condições favorecem a sua manifestação tais como o sexismo, machismo, racismo e desigualdade social. É um fenômeno complexo e multifatorial, que não pode ser compreendido somente na perspectiva individual sendo necessária uma visão sistêmica. Isto exige o planejamento de políticas públicas intersetoriais e que o reconhecimento da gravidade dessa violência se traduza em orçamento público.

É importante ressaltarmos que o contexto de violência sexual é muito amplo. Sintetizando esse contexto amplo de violação, mencionamos alguns exemplos dessas violações, tais como: abuso sexual; exploração sexual; estupro; pedofilia, entre outras. As dúvidas acerca dessa temática ainda pairam, posto que os estudos produzidos pela literatura, ainda não dão conta de como tais manifestações se apresentam e/ou acontecem no convívio social. A busca por mais pesquisas nesse campo de conhecimento ainda se faz necessária e urgente. Não há ideias, conceitos e/ou classificações da violência sexual que sejam ditas como verdades puras e acabadas, posto que as mais diversas formas de interpretações podem ser refutadas por outros/as estudiosos/as (MINAYO, 2006).

Por conseguinte, citamos a Lei no 13.431/2017 (BRASIL, 2017) que define a violência sexual como qualquer conduta que constranja a criança e o/a adolescente a praticar ou presenciar conjunção carnal ou qualquer outro ato libidinoso, inclusive exposição do próprio corpo em foto ou vídeo por meio eletrônico ou não, e esta forma de violação de Direitos Humanos compreende:

a) abuso sexual, entendido como toda ação que se utiliza da criança ou do adolescente para fins sexuais, seja conjunção carnal ou outro ato libidinoso, realizado de modo presencial ou por meio eletrônico, para estimulação sexual do agente ou de terceiros;

b) exploração sexual comercial, entendida como o uso da criança ou do adolescente em atividade sexual em troca de remuneração ou qualquer outra forma de compensação, de forma independente ou sob patrocínio, apoio ou incentivo de terceiro, seja de modo presencial ou por meio eletrônico;

c) tráfico de pessoas, entendido como o recrutamento, o transporte, a transferência, o alojamento ou o acolhimento da criança ou do adolescente, dentro do território nacional ou para o estrangeiro, com o fim de exploração sexual, mediante ameaça, uso de força ou outra forma de coação, rapto, fraude, engano, abuso de autoridade, aproveitamento de situação de vulnerabilidade

Periódico Horizontes - USF - Itatiba, SP - Brasil - e021067 
ou entrega ou aceitação de pagamento, entre os casos previstos na legislação (BRASIL, 2017, art. 4).

São tipos de violências que se enraízam cada vez mais na sociedade e em praticamente todas as camadas sociais. A nação brasileira necessita urgentemente de políticas públicas que venham a corroborar para enfrentamento dessas práticas de violação. A coletividade precisa ganhar visibilidade nesse cenário de lutas constantes, em que nem sempre é possível ter como direito, o mínimo que já é preconizado na nossa Constituição da República Federativa do Brasil de 1988 (BRASIL, 1988).

Para atingirmos aos objetivos propostos, optamos por uma pesquisa bibliográfica e documental, de caráter qualitativo. A primeira é caracterizada pelo uso de material já publicado, ou seja, de autores/as que discutem a temática, a saber: Silva e Oliveira (2020), Weiss e Pantoja (2019), Vieira et al. (2015), entre outros/as autores/as com o objetivo de colocar o/a pesquisador/a em contato direto com grande parte do material já escrito sobre o assunto da pesquisa (PRODANOV; FREITAS, 2013). A segunda trata da pesquisa documental a qual é realizada em documentos conservados no interior de órgãos públicos e privados de qualquer natureza, ou com pessoas - nesse contexto, nos reportamos ao Plano Municipal de Educação do município de Manaus/AM (MORESI, 2003). Já a abordagem qualitativa supõe o contato direto e prolongado do/a pesquisador/a com o ambiente e a situação que está sendo investigada, nesse caso, as bibliografias e as duas legislações de enfrentamento à violência sexual contra crianças e adolescentes. Segundo Lüdke e André (2007), a preocupação com o processo é muito maior do que com o produto, de modo que cabe ao/à pesquisador/a verificar como esse processo se manifesta nas atividades, nos procedimentos e nas interações cotidianas.

A partir do exposto, o presente texto é composto por três seções, a saber: (I) Política pública de Educação e violência sexual; (II) Marcos Legais de combate ao fenômeno da violência sexual contra crianças e adolescentes; (III) Plano Municipal de Educação: debater/garantir a Educação Sexual na escola é necessário e urgente.

\section{Política pública de educação e violência sexual}

Dialogar sobre políticas públicas, nos remete a dialogarmos acerca das relações sociais 
também, no sentido de que a sociedade como um todo - principalmente as classes menos favorecidas - possa ter garantida, pelo menos, uma condição mínima para sobreviver, ao passo que a dignidade também se faz imprescindível nesse contexto de garantias de direitos. Esse debate perpassa questões muito mais amplas, tais como, a saúde, a alimentação, a moradia, o transporte, a segurança, o lazer, qualidade de vida, até mesmo por questões de gênero, sexualidades, de identidades, o contexto da violência sexual, entre outras práticas sociais (OLIVEIRA, 2017).

As políticas públicas educacionais são imprescindíveis para a organização social, sobretudo, para direcionar os rumos da Educação almejada pela sociedade - com qualidade, equidade - e como alcançar esse patamar. São elas que possibilitarão a todos/as indivíduos/as uma Educação que promova a equidade, qualidade, a garantia e proteção dos/as cidadãos/ãs a toda e qualquer forma de violação de direitos. Aqui mencionamos a escola, a qual se desencadeia - ou pelo menos deveria - todas essas políticas. A exemplo dessas políticas públicas - ações governamentais - podemos citar a Lei de Diretrizes e Bases da Educação Nacional (Lei noo. 9.394/1996) (BRASIL, 1996), o Plano Nacional de Educação (BRASIL, 2014a), o Plano Municipal de Educação: Caderno de Orientações (BRASIL, 2014b), as quais priorizam as questões relacionadas à Educação brasileira e o tipo de cidadão/ã que pretende formar ao longo de toda a escolarização. Diante disso, vale ressaltar o papel do/a professor/a como alguém que vai além de compor um espaço, de uma posição de educador/a, mas que é um ser social e político, que deve considerar em sua prática grupos que historicamente se constituíram diante de uma relação de desigualdade social e econômica. Além do mais, deve posicionar-se frente a uma Educação que apenas repõe peças e se oponha a ela e a desnaturaliza como tal (TORRES, 2018).

Convém ressaltarmos que o cenário político nacional tem sido de instabilidade nos últimos cinco anos. O Brasil enfrentou em 2016, a destituição da primeira presidenta do governo (Dilma Rousseff/PT) e medidas que já estavam sendo elaboradas no governo anterior ao impeachment ganham visibilidade, força e aprovação das camadas conservadoras da nossa sociedade. Na Educação não é diferente. A chamada "crise na Educação" volta à pauta e começa a ser discutida com mais intensidade, inclusive por setores externos à Educação - economistas, empresários que há muito tempo exercem influência na elaboração de políticas públicas educacionais, principalmente em países em desenvolvimento - os chamados emergentes (TORRES, 2018). 
Muito oportuno destacarmos que a adesão à discussão dos rumos que a escola precisa tomar e sua função social, passaram a ser discutidas por músicos/as, políticos/as, economistas, artistas, sociedade civil organizada, movimentos sociais etc. e tem como um de seus principais meios difusores as mídias qual sejam, televisão, rádio, internet, entre outros/as. Essa discussão que abrange vários segmentos sociais, é um ponto fundamental e necessário para a retomada, luta e garantia de uma Educação pública, que não apenas oferte vagas nas escolas, mas garanta a permanência desta, com qualidade, equidade e que atenda com a mesma prioridade de ensino, todas as camadas sociais brasileiras.

Convém destacar que todas e quaisquer políticas públicas são construídas e legitimadas, a partir de uma ideologia elitista do Estado, dos grupos que governam, de uma elite que domina e que está no poder, dotada de condição superior socioeconomicamente, que lidera a soberania e as principais decisões de uma sociedade. Nesse cenário, encontra-se a escola, que nesse contexto, acaba por refletir e ou reproduzir essas práticas dominantes, a partir de documentos oficiais, que de certo modo, são elaborados por meio da ótica elitista, que produz e legitima o capital e as suas instituições, como por exemplo o mercado e o Estado (GIROUX, 1986).

Por conta disso, é fundamental a articulação da sociedade civil organizada com os movimentos sociais, a fim de buscar legitimar as necessidades sociais em forma de política pública. Entendendo os movimentos sociais como ações coletivas de caráter sociopolítico e cultural que viabilizam formas distintas de a população se organizar e expressar suas demandas, que adotam diferentes estratégias, que vão desde a denúncia até organizações maiores como por exemplo: marchas, concentrações, passeatas, negociações, estes são imprescindíveis para que a sociedade consiga obter êxito em suas pautas, reinvindicações e demandas, especialmente demandas no setor educacional (TORRES, 2018). Touraine (1989) já afirmava que os movimentos sociais são o coração, o pulsar da sociedade. Eles expressam energias de resistências ao velho que oprime ou de construção do novo que liberte. Sempre estiveram presentes em todas as sociedades.

Os movimentos sociais da Educação são processuais, históricos e ocorrem dentro e fora da escola ou em outros espaços institucionalizados, abrangem diferentes pautas e podem estar associados a uma Educação formal ou informal em diferentes níveis ou modalidades de ensino, conforme pontua Gohn (2016). As lutas concernentes à Educação formal/escolar têm, 
historicamente, a participação de associações de classe e sindicatos, os quais utilizam de greves e manifestações como estratégias para seus anseios (TORRES, 2018). São esses movimentos sociais que ao longo da história da sociedade brasileira têm conquistado direitos, garantias fundamentais em diversos setores da sociedade, principalmente no setor educacional, além de promover debates e contribuir para dar maior visibilidade à discussão do contexto da violência sexual contra crianças e adolescentes em nosso país.

A violência sexual é uma das violações de Direitos Humanos que mais causa danos na vida das pessoas - principalmente em crianças e adolescentes - qual sejam psicológicos, moral, físicos entre outros (OLIVEIRA, 2017). É uma realidade presente em praticamente todas as camadas sociais e em lugares inimagináveis/longínquos do Brasil.

Quando nos referimos em violência sexual, esta representa um campo de entendimento mais amplo. Significa dizer que é todo o abuso do poder pelo qual crianças e adolescentes são usados/as para gratificação sexual de adultos/as ou forçados/as a práticas sexuais. Consumando uma violação de direitos infanto-juvenil, negando a este grupo, o pleno desenvolvimento de sua sexualidade (BRAGA; RODRIGUES, 2018).

Com a incumbência de propor parcerias com órgãos públicos ou organizações da sociedade civil, o Brasil conta com a Ouvidoria Nacional de Direitos Humanos (ONDH), a qual tem por objetivo fortalecer a rede de proteção e defesa dos Direitos Humanos, organizar os fluxos de encaminhamentos, procedimentos de acolhida, atendimento e para o monitoramento das denúncias. As denúncias, manifestações e outros atendimentos realizados diariamente, transformam-se em uma importante fonte de dados, posto que potencializam o processo de formulação e implementação de políticas públicas nas diferentes esferas governamentais, qual sejam, municipal, estadual, federal e distrital. Ademais, permite identificar as regiões brasileiras com maior incidência de violações, fator essencial para o melhor planejamento e desenho das políticas públicas de proteção à Direitos Humanos, principalmente àqueles concernentes a crianças e adolescentes (MDH, 2019).

Oportuno salientarmos que o Disque 100 é uma importante ferramenta do governo federal o qual se caracteriza como mecanismo efetivo de proteção dos Direitos Humanos. Ele completou 15 anos de história no dia 06 de dezembro de 2018. O Disque 100 - ferramenta de rompimento do ciclo de violência - é ligado à $\mathrm{ONDH}$ e estabelece grande capacidade de 
interlocução com os principais órgãos da Rede de Proteção e Garantia de Direitos.

Para compreender a amplitude e a gravidade da violência sexual, recorremos aos dados oficiais, que mesmo considerando a subnotificação, apresentam números muito altos. Dentre as 159.063 denúncias registradas no Disque Direitos Humanos (Disque 100) no ano de 2019 em todo país, houve um aumento de $15 \%$, se comparado ao ano de 2018 . Representando 55\% desse total, com 86.837 denúncias, chama a atenção o grupo de crianças e adolescentes, considerando assim, o grupo vulnerável com maior número de denúncias no âmbito do Disque 100. Essas informações se referem a dados mais gerais da população brasileira. As violações de Direitos Humanos sofridas por crianças e adolescentes no ano do 2019 , representa, um total de $14 \%$ a mais do que no ano de 2018 (MDH, 2019).

Examinando os dados por região, observamos que a Região Sudeste concentra os maiores casos de denúncias - estados de São Paulo, Minas Gerais e Rio de Janeiro. Se compararmos os dados acerca da taxa de denúncias por números de habitantes - no caso, a cada 100 mil habitantes - constataremos que o Mato Grosso do Sul é o estado que mais concentra violações contra o público infanto-juvenil, chegando a uma taxa de 67,07 denúncias a cada 100 mil habitantes, seguido pelo Distrito Federal, com 62,61 e Rio Grande do Norte, com 58,45. Já no sentido inverso de denúncias, observamos os estados da Bahia, Paraná e Rio Grande do Sul com taxa desses registros abaixo da metade das máximas (ou seja, abaixo de 40 registros a cada 100 mil habitantes) e inferior à média nacional de 41,3 denúncias a cada 100 mil habitantes. Ademais, nessa mesma linha de análise, percebemos que o estado de Roraima registrou um crescimento de 62,90\% de 2018 a 2019, seguido por Amapá com 54,48\% e o Amazonas que registrou também, nesse mesmo período, um aumento de 41,59\% (MINISTÉRIO DA SAÚDE, 2020).

Diante desse contexto de violações de Direitos Humanos contra crianças e adolescentes evidencia-se que, em $72,3 \%$ dos registros a vítima é do gênero feminino e o estupro é a violência mais reportada $(50,6 \%)$, o que equivale a 48,84 casos por dia. De acordo com esses dados a violência sexual atinge mais as crianças e as adolescentes do gênero feminino (82\%), e são cometidas, na maioria dos casos, na casa da vítima (45\%) ou na casa do suspeito ( $28 \%$ ), por pai ou padrasto (40\%), e ainda, o suspeito configura-se do sexo masculino ( $87 \%$ ) e possui idade entre 25 a 40 anos (62\%) (MDH, 2020). 
Além desses números, o Atlas da Violência 2018 também nos auxilia a pensarmos a dimensão da violência sexual contra crianças e adolescentes, evidenciando, no ano de 2016, o número de 49.477 casos de estupros, mostrando que as crianças estão entre as principais vítimas de estupro no Brasil (CERQUEIRA et al., 2018). Ressaltamos, mais uma vez, a necessidade de que os direitos desse público sejam resguardados, de maneira que a instituição escolar precisa ser um espaço social e cultural de formação dos sujeitos, contribuindo na orientação de crianças e adolescentes, auxiliando na descoberta de casos de violência sexual e encaminhando os possíveis casos para os órgãos responsáveis.

Os dados revelam uma realidade violenta do ponto de vista da violência física, psíquica, moral entre outras, para com as crianças e os/as adolescentes desse país. É alarmante pensar que a cada uma (1) hora cerca de três crianças são violentadas sexualmente. Esse tabu precisa urgentemente ser "desmistificado" e "desconstruído, o qual reporta a ideia e/ou pensamento de que alguém tem poder sobre o/a outro/a, e a partir desse pensamento, presumir que pode violar o direito do/a outro/a (BORBA, 2020).

\section{Marcos legais de combate ao fenômeno da violência sexual contra crianças e adolescentes}

É imprescindível mencionarmos nesse contexto, a lei que dispõe sobre o Estatuto da Criança e do Adolescente (ECA), Lei no 8.069/1990 (BRASIL, 1990) e a Lei $n \cong 13.431 / 2017$ (BRASIL, 2017), que estabelece o sistema de garantia de direitos da criança e do/a adolescente vítima ou testemunha de violência, que alterou o texto do ECA. Essas leis vêm dar uma maior visibilidade e garantia no sentido de garantir mais proteção para o público infanto-juvenil e ao mesmo tempo punir aqueles/as que cometem os crimes de violação de Direitos Humanos, principalmente aqueles/as que violam a integridade sexual de crianças e adolescentes.

O Estatuto da Criança e do Adolescente, preconiza que escolas e educadores/as têm responsabilidades frente a esses casos de violência sexual e estabelece a obrigação de comunicar ao Conselho Tutelar os casos de suspeita ou confirmação de maus-tratos contra criança ou adolescente e, ocorrendo desrespeito a essa determinação, define a aplicação de multa a professores/as ou responsável pelo estabelecimento de ensino (BRASIL, 1990).

Não somente à escola e educadores/as cabe o papel de denunciar eventuais suspeitas de 
violência sexual, mas de toda a sociedade. Cada cidadão/ã tem o dever de colaborar com as autoridades responsáveis, no sentido da denúncia, para que se possa tomar as medidas cabíveis, sejam elas de punição do/a criminoso/a, de empoderamento da vítima, de enfrentamento aos casos desse tipo de violência.

Esse grave cenário nos leva a problematizar quais são as responsabilidades da política pública de educação no enfrentamento à violência sexual contra crianças e adolescentes. Para investigar essa questão realizamos uma pesquisa documental, de caráter qualitativo, com o objetivo de analisar quais são as responsabilidades da política pública de educação, definidas na legislação em vigor, no enfrentamento à violência sexual e de que forma as metas do Plano Municipal de Educação de Manaus tratam o tema verificando-se a existência ou não de coerência com essa legislação. Sobretudo quando notamos no ano de 2019, por exemplo, que os indicadores da Secretaria de Segurança Pública do Amazonas (SSP/AM, 2019), os quais revelaram 553 casos de estupro de vulnerável em Manaus/AM. Esses números demonstram a urgente e necessidade da discussão no seio das instituições públicas - e privadas - de ensino acerca da violação de direitos sexuais de crianças e adolescentes em nosso país.

Para responder a esse problema de pesquisa foi realizada uma análise de duas legislações sobre o enfrentamento à violência sexual contra crianças e adolescentes aprovadas nos últimos cinco anos, que apresentam novas demandas para as políticas públicas de educação e para as escolas enquanto integrantes do Sistema de Garantia de Direitos e da rede de proteção prevista no Estatuto da Criança e do Adolescente (ECA). A primeira é a Lei no 13.431 que foi aprovada em 04 de abril de 2017 e criou um subsistema de garantia de direitos da criança e do/a adolescente vítima ou testemunha de violência (BRASIL, 2017). A segunda é o Decreto no 9.603, de 10 de dezembro de 2018 que regulamentou a Lei no 13.431/2017 (BRASIL, 2017).

De acordo com a Lei no 13.431/2017 deve haver uma integração das políticas de atendimento a crianças e adolescentes implementadas nos sistemas de justiça, segurança pública, assistência social, educação e saúde. Essas políticas devem adotar ações articuladas, coordenadas e efetivas voltadas ao acolhimento e atendimento integral às vítimas de violência. A Lei estabelece no Artigo 13 a obrigação de comunicar ao serviço de recebimento e monitoramento de denúncias, ao Conselho Tutelar ou à autoridade policial toda e qualquer suspeita de violência contra criança ou adolescente, praticada em local público ou privado. 0 
Conselho Tutelar e a autoridade policial, por sua vez, deverão cientificar imediatamente o Ministério Público. Além da obrigação de comunicar o fato, as políticas públicas, dentre elas a educação, devem promover campanhas educativas que colaborem para disseminar informações que ajudem na identificação das violações de direitos de crianças e adolescentes, na divulgação dos serviços de proteção e fluxos de atendimento e no conhecimento dos direitos a serem garantidos (BRASIL, 2017).

As esferas governamentais - Federal, Estadual, Municipal e Distrital - devem promover políticas públicas voltadas para o debate dessa temática tão evidente hoje nos mais variados segmentos da sociedade. A promoção dessas políticas, quanto às suas formulações, implementações e efetivações, deve levar em consideração a participação popular, dar mais visibilidade e voz aos anseios coletivos. E esse é o grande desafio que tem a sociedade brasileira, o desafio de buscar o efetivo exercício da cidadania, da democracia, do pleno direito de participar, junto aos governos, das tomadas de decisões importantes que as camadas mais vulneráveis do nosso país precisam. A educação é o caminho para se conseguir uma sociedade melhor, fraterna, igualitária, que promova equidade de direitos, e para que isso ocorra, o Estado deve contemplar as múltiplas realidades - cultural, social, econômica, entre outras - da população (SILVA; OLIVEIRA, 2020).

As ações realizadas em todos os órgãos da rede de proteção devem observar algumas diretrizes, conforme estabelece o artigo 14: avaliação e atenção às necessidades da vítima decorrentes da ofensa sofrida; capacitação interdisciplinar continuada, preferencialmente conjunta, dos/as profissionais dos diferentes serviços; estabelecimento de mecanismos de informação, referência, contrarreferência e monitoramento; planejamento coordenado do atendimento e do acompanhamento, respeitadas as especificidades da vítima ou testemunha e de suas famílias; celeridade do atendimento após a revelação da violência; priorização do atendimento em razão da idade ou de eventual prejuízo ao desenvolvimento psicossocial, garantida a intervenção preventiva; mínima intervenção dos/as profissionais envolvidos/as; e monitoramento e avaliação periódica das políticas de atendimento. Destaca-se ainda a necessidade de preservação da confidencialidade (BRASIL, 2017).

De fato, para que os mecanismos de proteção, de enfrentamento à violência sexual infanto-juvenil sejam efetivados de forma a garantir tal proteção e/ou enfrentamento, é preciso 
que antes de tudo, se conheça o que realmente significa esse contexto da violência sexual. Daí a importância do debate acerca dessa temática junto à população, e que essa discussão perpasse as diversas classes sociais e chegue até as crianças e os/as adolescentes. Estes, precisam compreender por meio do diálogo em sala de aula, por meio de campanhas educativas, o verdadeiro sentido dessa prática delituosa cometida contra esse público. A partir desse conhecimento e empoderamento, é que os passos iniciais, no sentido da criação, elaboração de mecanismos de proteção e enfrentamento da violência sexual, é que a sociedade pode colher resultados favoráveis de proteção e combate desse tipo de violação de Direitos Humanos (SILVA; OLIVEIRA, 2020).

O Decreto no 9.603/2018 (BRASIL, 2018) estabelece ainda que os órgãos que compõem o sistema de garantia de direitos e a rede de proteção são responsáveis pela detecção dos sina is de violência (Art. 7) devendo garantir condições de atendimento adequadas para que crianças e adolescentes vítimas de violência ou testemunhas de violência sejam acolhidas, protegidas e possam se expressar livremente em um ambiente compatível com suas necessidades, características e particularidades (Art. 8).

Caso os/as profissionais da educação identifiquem ou lhes seja revelado por uma criança ou um/a adolescente atos de violência, estes/as devem acolher a criança ou o/a adolescente e informar sobre os direitos e os procedimentos de comunicação à autoridade policial e ao Conselho Tutelar conforme estabelece o artigo 11. Em seguida devem comunicar o Conselho Tutelar e encaminhar a criança ou o/a adolescente, quando couber, para atendimento emergencial em órgão do sistema de garantia de direitos da criança e do/a adolescente vítima ou testemunha de violência. Além disso, cabe às redes de ensino a responsabilidade de implementação de programas de prevenção à violência sexual.

\section{Plano municipal de educação: debater/garantir a educação sexual na escola é necessário e urgente}

Destacamos que uma das formas de prevenir a violência sexual contra crianças e adolescentes é por meio da Educação Sexual, que - a partir de práticas planejadas e com materiais adequados - tem como um dos objetivos educar esse público para os limites do toque. 
Convém salientarmos que a Educação Sexual na escola deve se dar no âmbito pedagógico, não tendo, portanto, um caráter terapêutico. É um trabalho que deve ser compreendido como um espaço para que, por meio de dinâmicas, de ações pedagógicas planejadas, possamos problematizar temáticas, levantar questionamentos e ampliar a visão de mundo e de conhecimento. A escola é, sem dúvida, o ambiente mais propício e que nela deve-se imprescindivelmente, discutir os diferentes tabus, preconceitos, crenças e atitudes na nossa sociedade, relacionados à sexualidade. Isso deve acontecer de forma natural, planejada, científica, sem ditar normas de "certo" ou "errado", o que "deve" ou "não deve" fazer ou impor os seus valores, acreditando que é melhor para o/a seu/sua estudante - o que pode não ser! Cabe ao/à professor/a o papel de ser mais um/a "dinamizador/a de ideias" do que um/a “expositor/a da matéria” (RIBEIRO, 2020).

Discutir/dialogar a Educação Sexual na escola se faz necessário e urgente. E essa discussão com crianças e adolescentes na sala de aula, encontram-se os amparos legais em nossa Legislação Brasileira. Oportuno mencionarmos os parâmetros que contemplam o trabalho de Sexualidade e Prevenção, a saber: Portaria Interministerial Ministério da Saúde e Ministério da Educação - no 796 (MINISTÉRIO DA SAÚDE, 1992); Lei de Diretrizes e Bases da Educação Nacional - LDBEN, Lei no 9.394/1996 (BRASIL, 1996); Parâmetros Curriculares Nacionais (BRASIL, 1997); Orientações Curriculares Nacionais para o Ensino Médio (MEC, 2021); Marco legal: saúde, um direito de adolescentes (MINISTÉRIO DA SAÚDE, 2005). Todos esses parâmetros garantem o amparo legal para que os/as profissionais da Educação possam discutir/dialogar assuntos/ações que contemplem a temática da Sexualidade no âmbito escolar. É evidente que a legislação dá amparo num lado, por outro, é a qualidade das ações pedagógicas e sua aceitação pela sociedade e importância na Educação de crianças e adolescentes, que será a melhor garantia para a realização dessas ações no espaço escolar (RIBEIRO, 2020).

A operacionalização dessas ações exige planejamento e o Plano Municipal de Educação (PME) é um documento imprescindível para tal, pois tem força de lei, e é importante para evitar a descontinuidade das políticas públicas de educação tendo vigência por dez anos. O PME estabelece as metas e estratégias que serão colocadas em ação pelo município para garantir o que o direito à educação de qualidade avance cada vez mais. Por tudo isso ele se converte no principal instrumento da política pública educacional. Mas para isso, é preciso considerar as 
múltiplas realidades e discutir questões importantes para a garantia do acesso à educação de qualidade e socialmente referenciada.

Partimos do pressuposto que o PME é um recurso de gestão importante para a consolidação de políticas de estado e deve abordar as problemáticas que atingem crianças e adolescentes, analisamos o PME de Manaus para identificar quais metas e estratégias referem às responsabilidades estabelecidas na legislação. O PME de Manaus/AM foi aprovado na Câmara Municipal de Manaus pela Lei 2000 em 24 de junho de 2015. Contém 20 metas e 218 estratégias educacionais (MANAUS, 2015).

Até agora discutimos sobre a função dos Planos Municipais de Educação (PME) no contexto escolar, além da escola enquanto um ambiente propício de revelação de casos de violência sexual contra crianças e adolescentes. A partir desse cenário, vamos problematizar, a urgência dos PME para o trabalho acerca da violência sexual contra crianças e adolescentes, em uma perspectiva de que esse documento oficial pode contribuir para a organização de um trabalho efetivo em relação a esse tema, que por vezes é visto como um tabu social.

A sociedade como um todo tem o dever de proteger as crianças e os/as adolescentes, de modo que lhes sejam garantidos direitos fundamentais como saúde, educação, lazer, proteção. A Constituição da República Federativa do Brasil define que é dever/responsabilidade da família, da sociedade e do Estado assegurar à criança e ao/à adolescente "[...] o direito à vida, à saúde, à alimentação, à educação, ao lazer, à profissionalização, à cultura, à dignidade, ao respeito, à liberdade e à convivência familiar e comunitária" (BRASIL, 1988, art. 227); o mesmo artigo ainda estabelece que esse grupo deve estar a salvo "[...] de toda forma de negligência, discriminação, exploração, violência, crueldade e opressão" (BRASIL, 1988, art. 227).

E, para que essa proteção seja - de fato - alcançada, é fundamental que as instituições brasileiras operacionalizem as suas ações baseadas em documentos oficiais, além de práticas inovadoras e eficazes a partir da especificidade de cada setor. Na Educação que atende crianças e adolescentes, podemos encontrar a Lei de Diretrizes e Bases da Educação Nacional (BRASIL, 1996), as Diretrizes Curriculares Nacionais da Educação Básica (BRASIL, 2013), o Plano Nacional de Educação (BRASIL, 2014a). E, em se tratando mais especificamente dos municípios, nos deparamos com os PME (os últimos foram promulgados em 2015), que estabelecem metas e estratégias educacionais voltadas para a sua localidade. 
Os PME devem apresentar um diagnóstico da realidade local, a fim de conseguir estipular ações - sobretudo administrativas e pedagógicas - que contribuam com a melhoria da qualidade educacional, além de propor o trabalho com valores sociais e culturais, a não discriminação entre as pessoas, o combate e a prevenção das mais variadas formas de violência. E é sobre esse último aspecto que vamos nos debruçar neste momento.

Vieira et al (2015, p.3415) são enfáticas ao estudarem sobre capacitação de profissionais para o enfrentamento da violência sexual contra crianças e adolescentes em quatro capitais brasileiras (Porto Alegre/RS, Campo Grande/MS, Belém/PA e Fortaleza/CE), as autoras defendem que é fundamental a construção de um "[...] plano de capacitação sobre violências e direitos sexuais de crianças e adolescentes e, em especial, sobre violência sexual, tratando das formas de identificar e atuar nestas situações". Esse trabalho deve ser realizado a partir da tarefa conjunta das áreas que atendem crianças e adolescentes, de modo que incluam "[...] (1) planejamento de oferta de atividades; (2) metas de cobertura do número de profissionais das redes; e (3) registro do número de capacitações, conteúdos, sistematicidade e profissionais envolvidos" (VIEIRA et al, 2015, p.3415).

Nesse sentido, os PME poderiam dar pistas para esse trabalho, a partir do diagnóstico de casos de violência sexual contra crianças e adolescentes nos respectivos municípios como forma de alerta; propor capacitação dos/a profissionais da Educação para identificar suspeitas e casos dessa forma de violência e reportar tais casos às autoridades competentes; apresentar materiais científicos que contribuam na prevenção e no combate à violência sexual; propor espaços de debate sobre o assunto. Mas, para todas essas ações, é basilar que tais documentos oficiais - ao menos - citem a violência sexual, fazendo com que o tema deixe de ser um tabu e haja diálogo sobre ele. Quando um assunto tão importante como esse é redigido em um documento oficial, trabalhadores e trabalhadoras da Educação, comunidade escolar, dirigentes escolares podem cobrar do poder público ações afirmativas.

Intriga-nos, também, que não há estudos relacionando os PME e a violência sexual contra crianças e adolescentes. Encontramos apenas uma pesquisa de doutoramento, em que Oliveira (2017), ao analisar dezessete PME do Estado do Paraná, concluiu que quase $53 \%$ dos documentos não mencionam a violência sexual contra crianças e adolescentes uma violação tão frequente no país. O autor ainda pondera que é fundamental que todas as esferas governamentais "[...] se 
articulem para possibilitar discussões e práticas acerca do tema com todos/as os/as profissionais da Educação, bem como com responsáveis, comunidade escolar, organizações governamentais e não-governamentais etc." (OLIVEIRA, 2017, p.121). Além de pontuar nos documentos os aspectos da violência sexual infantil e adolescente (o que por si só não basta), é preciso vontade política para instaurar um trabalho coerente e científico sobre a questão, além de fiscalização acerca de sua realização, com o objetivo de diminuir os casos de violência sexual.

Ao analisarmos a minuta do PME de Manaus/AM encaminhada à Câmara dos Vereadores a palavra "violência" aparece 5 vezes, "sexual" 3 vezes, "gênero" 5 vezes e a palavra "prevenção" aparece 4 vezes no documento. No entanto na versão aprovada a palavra "gênero" é excluída do documento e reduzidas a frequência das palavras "sexual" e "prevenção". A única que permanece na mesma quantidade é a palavra "violência". Essas mudanças ocorreram em meio a embates protagonizados por movimentos religiosos que transformaram a Câmara Municipal de Manaus, no dia da votação do PME, em um "[...] ambiente hostil [...] com base no argumento da preservação da família" (WEISS; PANTOJA, 2019, p.6). Junqueira (2017) afirma que esses grupos utilizam a "ideologia de gênero" como estratégia para estabelecer um pânico moral na sociedade a fim de sustentar mobilizações extremamente conservadoras.

Damos destaque ao termo "ideologia de gênero" que significa expressão fantasiosa, inverdadeira, sem cunho científico e sem lastro com a realidade. Ou ainda, é apontada como uma forma de doutrinação neototalitária, de raiz marxista, ateia, camuflada em discursos acerca da emancipação, liberdade e igualdade. E mais ainda, é uma invenção que ecoa enquanto componente de uma (re)configuração retórica mais ampla, expressão de um sistema de crenças e de um sistema de representação de matriz católica (Vaticana) conservadora e tradicionalista, que, em diferentes graus e circunstâncias, pode ser acionado e vir a orientar, abalizar ou simplesmente compor, entre paráfrases e reformulações, enunciados produzidos ou reelaborados em diversos campos sociais (JUNQUEIRA, 2018).

Uma única estratégia do PME/Manaus aborda diretamente a questão da violência sexual: Estratégia - 7.25: Garantir e ampliar políticas públicas de segurança e combate à violência na escola, inclusive pelo desenvolvimento de ações destinadas à capacitação dos/as profissionais da educação para deteç̧ão dos sinais de suas causas, como a violência doméstica e sexual, resguardando a integridade física e moral da vítima, favorecendo a adoção das providências 
adequadas para promover a construção da cultura de paz e um ambiente escolar dotado de segurança para a comunidade

Embora seja um início de ações para práticas acerca do combate à violência sexual contra crianças e adolescentes, é uma referência insuficiente para dar conta do enorme desafio que é a prevenção à violência sexual ou mesmo o acolhimento e a atenção aos possíveis casos revelados na escola. Uma limitação das iniciativas empreendidas pelo estado brasileiro refere-se à ausência de uma pauta afirmativa dos direitos sexuais de crianças e adolescentes. Não somente é necessário e urgente combater a violência, mas é antes de tudo imprescindível preveni-la. A despeito da existência de educadoras/es na Secretaria Municipal de Educação com formação e experiência na promoção da equidade de gênero, as diretrizes da gestão municipal não demonstram compromisso com essa pauta.

Em 2017, outro movimento em torno do tema levou à aprovação de uma Lei Municipal, que proibia "[...] a inserção, na grade curricular das escolas do município de Manaus, a orientação política pedagógica aplicada à implantação e ao desenvolvimento de atividades pedagógicas que visem à reprodução do conceito de ideologia de gênero" e definia "ideologia de gênero a ideologia segundo a qual os dois sexos, masculino e feminino, são considerados construções culturais e sociais" (MANAUS, 2017, [n. p.]). Um movimento que mobilizou educadores/as do ensino básico e superior para produzir subsídios e apresentar ao Ministério Público requerimento questionando a legitimidade desta lei.

O Tribunal de Justiça do Amazonas (TJAM) deferiu uma Ação Direta de Inconstitucionalidade (ADI) em fevereiro de 2019, a Câmara Municipal recorreu e a decisão foi ratificada pelo STF mantendo o acórdão do Pleno do TJAM que, por unanimidade de votos dos/as desembargadores/as da Corte do Amazonas, declarou a inconstitucionalidade da Lei Municipal n.o 439/2017. A Desembargadora Carla dos Santos Reis, relatora da ADI afirmou:

[...] Abdicar das questões de gênero e da orientação sexual, assim como deixar de esclarecer sobre questões biológicas, da identidade de gênero e da sexualidade, não inviabiliza a experiência humana e suas singularidades, mas tão somente soma com a desinformação de nossos alunos e contribui para a perpetuação de estigmas e da aflição que deles decorrem (TRIBUNAL DE JUSTIÇA DO AMAZONAS, 2019, p.16). 
Diante do exposto, se torna necessário debater/discutir a Educação Sexual no espaço escolar, e acima de tudo, deve se constituir de ações implícitas nos documentos educacionais Projeto Político-Pedagógico, por exemplo - que regem todas as ações pedagógicas da escola. É um assunto que precisa ganhar visibilidade, ser discutido cada vez mais no contexto escolar. A retórica da "ideologia de gênero", que tentam por meio de leis, abdicar das questões de gênero e da orientação sexual, são na verdade mais uma forma de tentar amordaçar professores e professoras desse país.

\section{Considerações finais}

De fato, os números apresentados nessa pesquisa acerca da violência sexual contra crianças e adolescentes são alarmantes. Estes, representam um total de 55\% (86.837 denúncias) de todas as denúncias de violação de Direitos Humanos registradas no território nacional. Um aumento de 14\% a mais do que o registrado no ano de 2018 (MDH, 2019). Nesse contexto, a Região Sudeste apresenta o maior número de casos de denúncias em todo território brasileiro, representados pelos estados do Rio de Janeiro, Minas Gerais e São Paulo (MINISTÉRIO DA SAÚDE, 2020). Destacamos que qualquer número de caso de violência sexual precisa ser combatido, sobretudo a partir de Políticas Públicas de enfrentamento do problema, vontade política para exercer práticas de prevenção, fiscalização de aplicação das leis oficiais.

São preocupantes a quantidade de registros de violações sexuais contra o público infantojuvenil. É preciso que a sociedade se mobilize, se organize coletivamente para que os movimentos sociais ganhem força e voz junto às instâncias superiores que governam essa nação. A busca coletiva deve priorizar a participação nas tomadas de decisões governamentais, principalmente acerca da formulação, implementação e efetivação das políticas públicas de enfrentamento à violência sexual contra crianças e adolescentes. Os dados apresentados aqui, mostram essa realidade social brasileira. A sociedade civil organizada, os movimentos sociais e toda a população precisam urgentemente combater essa prática de violação de direitos que tantos transtornos - físico, psíquico, moral, entre outros - causam a crianças e adolescentes.

A partir do exposto, defendemos a urgência de que os PME apresentem o tema de violência sexual contra crianças e adolescentes em suas páginas, propondo discussões e práticas 
de combate a essa forma de crime tão cruel, com o objetivo de problematizar o assunto, proteger esse grupo vulnerável e combater os casos. O primeiro passo é mencionar o assunto; para que na sequência sejam pensadas ações para o enfrentamento a essa violação dos Direitos Humanos, fazendo valer as leis que tanto apontam sobre a proteção de crianças e adolescentes.

É imprescindível mencionarmos o papel crucial que tem a escola na disseminação das discussões, no debate e nas orientações acerca dessa temática tão discutida hoje nas mídias, nos movimentos sociais de todo o Brasil. Discutir/debater a sexualidade na escola, é algo tão necessário e urgente para que tanto as crianças e os/as adolescentes se empoderem desse conhecimento e ganhem autonomia e coragem para denunciar seus/suas supostos/as violentadores/as.

Ainda destacamos que com o avanço de pautas neoconservadoras - a exemplo da "ideologia de gênero" - é fundamental que os/as trabalhadores/as escolares tenham acesso à formação científica sobre aspectos relacionados a gênero e sexualidade, de maneira a contribuir no combate e prevenção da violência sexual. A escola, a partir do conhecimento científico, se torna um dos lugares mais importantes e eficazes de discussões e práticas a fim de manter a garantia dos Direitos Humanos.

É basilar que, por meio da Educação Sexual Escolar, crianças e adolescentes adquiram conhecimento sobre os limites do seu corpo, os limites do toque, sobre práticas invasivas, sobre práticas consideradas violentas. O primeiro passo é o conhecimento que - em conjunto com a compreensão da dimensão do problema - pode contribuir para a diminuição dos casos de violência sexual. Além disso, é fundamental que haja campanhas de incentivo à denúncia de casos de violação dos direitos sexuais, com o intuito de garantir a punição aos/às violentadores/as e propiciar tratamento adequado às vítimas.

Contudo, ressaltamos ainda que o PME do município de Manaus/AM é o documento educacional fundamental para que essas práticas de violação de direitos contra o público infanto-juvenil sejam enfrentadas com mais imponderação no espaço escolar. É por meio desse documento que as escolas do município podem criar mecanismos de prevenção e/ou combate do problema. Criar uma rede de proteção é um primeiro passo crucial nessa jornada. Esta deve envolver toda a comunidade escolar - gestor/a, professor/a, pedagogo/a, administrativos - e demais membros da sociedade - pai, mãe, responsáveis - e que atue tanto dentro quanto fora 
da/s escola/s do município. E esta criação de uma rede de proteção no âmbito escolar, além de ser uma tarefa desafiadora, precisa estar elencada nas metas e estratégias do PME. É por meio dessa rede atuante nas escolas, que possibilitará maior empoderamento às crianças e adolescentes acerca dessa violação, e estes/as, consequentemente, terão maior autonomia para denunciar seus/suas supostos/as violentadores/as.

\section{Referências}

BORBA, A. 16ㅇd dia do Simpósio Nacional de Fortalecimento do Sistema de Garantia de Direitos - Virtual, 2020. 1 vídeo (02h 40 min). Disponível em:

https://www.youtube.com/watch?v=oibaVrBFZNc\&t=548s. Acesso em: 29 out. 2020.

BRAGA, R.; RODRIGUES, L. S. A. Abuso e exploração sexual de crianças e adolescentes: estudo da Lei 13.431/2017. 2018. Disponível em: https://jus.com.br/artigos/67899/abuso-eexploracao-sexual-de-criancas-e-adolescentes-um-estudo-bibliografico-sobre-a-lei-n-13-4312017. Acesso em: 06 jan.2020.

BRASIL. Constituição da República Federativa do Brasil. Brasília: Presidência da República, 1988.

BRASIL. Lei no 8.069, de 13 de julho de 1990. Dispõe sobre o Estatuto da Criança e do Adolescente e dá outras providências. Brasília: Presidência da República, 1990. Disponível em: http://www.planalto.gov.br/ccivil_03/leis//8069.htm. Acesso em: 23 out. 2020.

BRASIL. Lei no 9.394 de 20 de dezembro de 1996. Estabelece as diretrizes e bases da educação nacional. Brasília: Presidência da República, 1996. Disponível em:

http://www.planalto.gov.br/ccivil_03/leis/19394.htm. Acesso em: 28 mai. 2019.

BRASIL. Secretaria de Educação Fundamental. Parâmetros curriculares nacionais: introdução aos parâmetros curriculares nacionais. Brasília: MEC/SEF, 1997. Disponível em: http://portal.mec.gov.br/seb/arquivos/pdf/livro01.pdf. Acesso em: 09 jan.2021.

BRASIL. Diretrizes Curriculares Nacionais da Educação Básica. Brasília: Ministério da Educação/Secretaria de Educação Básica, 2013.

BRASIL. Lei no. 13.005/2014. Plano Nacional de Educação. Brasília: Presidência da República, 2014a. Disponível em:

http://www.observatoriodopne.org.br/uploads/reference/file/439/documentoreferencia.pdf. Acesso em: 16 fev.2019.

BRASIL. O plano municipal de educação: caderno de orientações. Brasília: Ministério da Educação / Secretaria de Articulação com os Sistemas de Ensino, 2014b. Disponível em: 
https://pne.mec.gov.br/images/pdf/pne.pme.caderno de orientações.pdf. Acesso em: 02 mar. 2020.

BRASIL. Lei no 13.431, de 4 de abril de 2017. Estabelece o sistema de garantia de direitos da criança e do adolescente vítima ou testemunha de violência e altera a Lei no 8.069, de 13 de julho de 1990. Brasília: Presidência da República, 2017.

BRASIL. Decreto no 9.603, de 10 de dezembro de 2018. Regulamenta a Lei $n=13.431$, de 4 de abril de 2017, que estabelece o sistema de garantia de direitos da criança e do adolescente vítima ou testemunha de violência. Brasília: Presidência da República, 2018.

CERQUEIRA, D. et al. Atlas da violência 2018. Rio de Janeiro: Ipea, 2018.

GIROUX, H. Teoria crítica e resistência em educação (para além das teorias da reprodução). Petrópolis: Vozes, 1986.

GOHN, M. G. Movimentos sociais e lutas pela educação no Brasil: experiências e desafios na atualidade. In: REUNIÃO CIENTÍFICA REGIONAL DA ANPED SUL, 11. 2016, Curitiba. Anais Educação, movimentos sociais e políticas governamentais. Curitiba: Universidade Federal do Paraná, 2016, [n. p.]. (Conferência de encerramento).

JUNQUEIRA, R. D. Ideologia de gênero: a gênese de uma categoria política reacionária - ou: como a promoção dos direitos humanos se tornou uma ameaça à família natural. In: RIBEIRO, P. R. C.; MAGALHÃES, J. C. (orgs.). Debates contemporâneos sobre educação para a sexualidade. Rio Grande: FURG, 2017, p.25-52.

JUNQUEIRA, R. D. A invenção da ideologia de gênero: a emergência de um cenário políticodiscursivo e a elaboração de uma retórica reacionária antigênero. Psicologia Política. v.18. n.43, p.449-502, set./dez. 2018.

LÜDKE, M.; ANDRÉ, M. E. D. A. Pesquisa em educação: abordagens qualitativas. 2. ed. Rio de Janeiro/RJ: EPU, 2007.

MANAUS. Lei no 2000, de 24 de junho de 2015. Aprova o Plano Municipal de Educação e dá outras providências. Manaus: Câmara de Vereadores/as, 2015.

MANAUS. Lei no. 439 de 07 de março de 2017. Proíbe, na grade curricular das escolas do município de Manaus, as atividades pedagógicas que visem à reprodução do conceito de ideologia de gênero. Manaus: Câmara de Vereadores/as, 2017.

MINISTÉRIO DA MULHER, DA FAMÍLIA E DOS DIREITOS HUMANOS - MDH. Disque direitos humanos: relatório 2019. Brasília: Ministério da Mulher, da Família e dos Direitos Humanos, 2019. Disponível em:

https://crianca.mppr.mp.br/arquivos/File/publi/mmfdh/disque_100_relatorio_mmfdh2019.pdf . Acesso em: 25 nov.2020. 
MINISTÉRIO DA EDUCAÇÃO - MEC. Orientações Curriculares Nacionais para o Ensino Médio PCNEM, 2021. Disponível em: http://portal.mec.gov.br/component/content/article?id=13558. Acesso em: 10 jan. 2021.

MINAYO, M. C. S. Violência e saúde. Rio de Janeiro: Fiocruz, 2006. (Temas em Saúde collection). [online]. Disponível em: https://static.scielo.org/scielobooks/y9sxc/pdf/minayo9788575413807.pdf. Acesso em: 23 nov.2020.

MINISTÉRIO DA SAÚDE. Portaria Interministerial Ministério da Saúde e Ministério da Educação - no 796, de 29 de maio de 1992, 1992. Disponível em:

https://www.mprs.mp.br/legislacao/portarias/2096/. Acesso em: 10 jan.2021.

MINISTÉRIO DA SAÚDE. Marco legal: saúde, um direito de adolescentes, 2005. Disponível em: http://www.reprolatina.institucional.ws/site/respositorio/materiais_apoio/textos_de_apoio/M arco_legal_Saude_um_direito_de_adolescentes.pdf. Acesso em: 10 jan.2021.

MINISTÉRIO DA SAÚDE. Dados epidemiológicos Sinan. Sistema de Informação de Agravos de Notificação - Sinan, 2020. Disponível em: http://portalsinan.saude.gov.br/dadosepidemiologicos-sinan. Acesso em: 12 out. 2020.

MORESI, E. (org.). Metodologia da Pesquisa.Brasília: Universidade Católica de Brasília, 2003.

OLIVEIRA, M. Políticas públicas e violência sexual contra crianças e adolescentes: planos municipais de educação do Estado do Paraná como documentos de (não) promoção da discussão. 2017, 136f. Tese (Doutorado em Educação) - Universidade Estadual de Maringá, Maringá, 2017.

PRODANOV, C. C.; FREITAS, E. C. Metodologia do trabalho científico: métodos e técnicas da pesquisa e do trabalho acadêmico. Novo Hamburgo: Feevale, 2013.

RIBEIRO, M. Educação sexual. 2020, [n.p.]. Disponível em:

http://www.reprolatina.institucional.ws/site/respositorio/materiais_apoio/textos_de_apoio/E ducacao_Sexual.pdf. Acesso em: 10 jan.2021.

SILVA, I. R.; OLIVEIRA, M. Mesa redonda 5: democracia, direitos humanos e educação, 2020. 1 vídeo (02h $02 \mathrm{~min}$ ). Publicado pelo canal SEINPE 2020. Disponível em:

https://www.youtube.com/watch?v=mKCrrg1lux0. Acesso em: 09 dez. 2020.

SECRETARIA DE SEGURANÇA PÚBLICA - SSP/AM. Indicadores da Secretaria de Segurança Pública, 2019. Disponível em: http://transparencia.ssp.am.gov.br/. Acesso em: 09 jan.2021.

TORRES, N. E. Cenário político educacional e movimentos sociais: BNCC e reforma do ensino médio em foco. In: SILVA, E. D.; NASCIMENTO, J. F. (orgs.). Políticas públicas educacionais. Rio de Janeiro: Dictio Brasil, 2018, p.172-205. 
TOURAINE, A. Palavra e sangue. Campinas: Editora da UNICAMP, 1989.

TRIBUNAL DE JUSTIÇA DO AMAZONAS. Ação Direta de Inconstitucionalidade (ADI) no 400473530.2017.8.04.0000, 2019. Disponível em: https://jurisprudencia.s3.amazonaws.com/TJAM/attachments/TJAM_ADI_40047353020178040000_8fbc9.pdf?AWSAccessKeyld=AKIARMMD5JEAD4VJ344N\&Ex pires $=1610312155 \&$ Signature=IpVxImB2OZqiAOvZYE0sCKThW8Q\%3D. Acesso em: 10 jan.2021.

VIEIRA, L. J. E. S. et al. Capacitação para o enfrentamento da violência sexual contra crianças e adolescentes em quatro capitais brasileiras. Ciênc. Saúde Coletiva, Rio de Janeiro, n.20, v.11, nov. 2015.

WEISS, F.; PANTOJA, R. F. Embates acerca das discussões de gênero na escola e ideologia de gênero no legislativo em Manaus. In: REUNIÃO DA ANTROPOLOGIA DO MERCOSUL, 13.;

ANTROPOLOGIAS DO SUL, 13., 2019, Porto Alegre. Anais [...], Porto Alegre: ABA, 2019. p.6.

Recebido em janeiro 2021.

Aprovado em novembro 2021. 